\title{
Outcome of cesarean delivery in women with excessive weight gain during pregnancy
}

\author{
Pascal Foumane ${ }^{1 *}$, Emmanuel Mando ${ }^{1}$, Emile Telesphore Mboudou ${ }^{1}$, Julius Dohbit Sama ${ }^{1}$, \\ Walter Dobgima Pisoh ${ }^{1}$, Jacqueline Ze Minkande ${ }^{2}$ \\ ${ }^{1}$ Department of Obstetrics and Gynecology, Faculty of Medicine and Biomedical Sciences (FMBS), The University of Yaoundé 1, \\ Yaoundé, Cameroon \\ ${ }^{2}$ Department of Anesthesiology \& Reanimation, Faculty of Medicine and Biomedical Sciences (FMBS), The University of Yaoundé \\ 1, Yaoundé, Cameroon \\ Email: "pfoumane2004@yahoo.fr
}

Received 15 January 2014; revised 10 February 2014; accepted 17 February 2014

Copyright (C 2014 Pascal Foumane et al. This is an open access article distributed under the Creative Commons Attribution License, which permits unrestricted use, distribution, and reproduction in any medium, provided the original work is properly cited. In accordance of the Creative Commons Attribution License all Copyrights (C) 2014 are reserved for SCIRP and the owner of the intellectual property Pascal Foumane et al. All Copyright (C) 2014 are guarded by law and by SCIRP as a guardian.

\section{ABSTRACT}

The objective of this study was to assess the effects of excessive weight gain during pregnancy on the outcome of cesarean delivery. It was a cohort study comparing the outcome of cesarean delivery between 56 pregnant women with excessive weight gain during pregnancy and 75 pregnant women with no excessive weight gain during pregnancy, consecutively recruited at the Yaoundé Gyneco-Obstetric and Pediatric Hospital, Cameroon. In women delivered by cesarean section, excessive weight gain during pregnancy was found to predispose to: time interval from parietal incision to fetal extraction of more than five minutes, duration of cesarean section more than 60 minutes, blood loss more than $1000 \mathrm{ml}$ during surgery, postoperative maternal complications, especially sepsis, fetal weight $>3.5 \mathrm{~kg}$ and macrosomia. A systematic screening of excessive weight gain should be offered to all pregnant women, so as to prevent the adverse effects of excessive gestational weight gain on cesarean outcome.

\section{KEYWORDS}

Excessive Weight Gain; Pregnancy; Outcome;

Delivery; Cesarean Section; Cameroon

\section{INTRODUCTION}

In 2009, the United States' Institute Of Medicine (IOM) issued new gestational weight gain guidelines (Table 1)

${ }^{*}$ Corresponding author.
[1]. Excessive weight gain has been associated with gestational diabetes, gestational hypertension, preeclampsia, cesarean delivery, higher birth weight babies and childhood obesity [2-6]. Even though many studies have found a greater risk of cesarean delivery among women with excessive weight gain during pregnancy [2-4,6], little is known on the effects of excessive weight gain on the outcome of operative deliveries since the publication of the new pregnancy weight gain guidelines, especially in sub-Sahara Africa where an increase in operative deliveries rates has been observed [7]. The identification of cesarean complications occurring more frequently in the presence of excessive weight gain during pregnancy is an important step to reduce maternal and fetal morbidity related to excessive weight gain during pregnancy in our milieu. The objective of this study was therefore to assess the effects of excessive weight gain during pregnancy on the outcome of cesarean delivery.

\section{METHODS}

It was a cohort study comparing 56 pregnant women with excessive weight gain during pregnancy (case group)

Table 1. Institute of Medicine's recommendations for total weight gain during pregnancy, by pre-pregnancy body mass index [1].

\begin{tabular}{cc}
\hline $\begin{array}{c}\text { Prepregnancy Body } \\
\text { Mass Index (BMI) }\end{array}$ & Total weight gain range (kg) \\
\hline Underweight $\left(<18.5 \mathrm{~kg} / \mathrm{m}^{2}\right)$ & $\mathbf{1 2 . 5}-\mathbf{1 8}$ \\
Normal weight $\left(18.5-24.9 \mathrm{~kg} / \mathrm{m}^{2}\right)$ & $\mathbf{1 1 . 5 ~ - ~ 1 6}$ \\
Overweight $\left(25.0-29.9 \mathrm{~kg} / \mathrm{m}^{2}\right)$ & $\mathbf{7 - \mathbf { 1 1 . 5 }}$ \\
Obese $\left(\geq 30.0 \mathrm{~kg} / \mathrm{m}^{2}\right)$ & $\mathbf{5 - 9}$ \\
\hline
\end{tabular}


to 75 pregnant women with no excessive weight gain during pregnancy (comparison group), who were consecutively delivered by cesarean section, from February $15^{\text {th }}$ to May $15^{\text {th }} 2013$, at the Yaoundé Gyneco-Obstetric and Pediatric Hospital, Cameroon. After approval of the protocol by the ethical committee of the hospital, all pregnant women admitted in the theatre for cesarean section and who gave their informed consent, were recruited into the study. All women having a cesarean delivery were given prophylactic enoxaparine and antibiotics (antibioprophylaxis or antibiotherapy). Each woman was counseled about the study and her consent was obtained prior to recruitment. A pretested questionnaire was administered by an investigator and the women were followed up from inclusion into the study, to discharge from the hospital. The variables studied were: maternal age, parity, gestational age, indication of the cesarean section, type of cesarean section (emergency or elective), grade of the surgeon, type of anesthesia, the difficulties in performing spinal anesthesia, type of parietal incision, time interval from incision to fetal extraction, difficulties in extracting the baby, duration of surgery, presence of fetal trauma, evaluation of blood loss, fetal birth weight, post-partum pelvic infection, fifth minute Apgar score, duration of hospital stay, newborn death. The early pregnancy weight available in the women's files was used to calculate body mass index in order to classify women according to the 2009 Institute Of Medicine’s guidelines. The height was measured at inclusion. For the calculation of the minimal sample size for each group, it was assumed that gestational excessive weight gain would increase the rate of excessive blood loss during cesarean section from $2 \%$ found by KOLAS et al. [8] to an expected figure of $22 \%$. The calculated minimal sample size using the formula proposed by SCHULZ et al. [9] was 51 subjects for each group with chosen precision and power respectively of $5 \%$ and $90 \%$. Statistical analysis was done using Epi info 3.5.3 and SPSS 12.0 software. The difference was statistically significant for $\mathrm{P}<0.05$. Pearson's Chi square and Fisher's exact test were used to compare proportions, while the Student's test was performed to compare means. The difference was statistically significant for $\mathrm{P}<0.05$. Relative risk $(\mathrm{RR})$ was calculated to measure the association between excessive weight gain and outcome.

\section{RESULTS}

One hundred and thirty-one pregnant women were delivered by cesarean section during the recruitment period. Among them, 56 (56/131; 42.7\%) had an excessive weight gain (case group) while 75 (75/131; 57.3\%) had no excessive weight gain (comparison group). The women with excessive weight gain had a mean age of $30.6 \pm 5.2$ years versus $29.1 \pm 6.2$ years for women with no excessive weight gain $(\mathrm{P}=0.66)$.

Among the preoperative variables analyzed (Table 2), parity $\geq 1$ was the only identified risk factor of excessive gestational weight gain in this study $(\mathrm{P}=0.01$; $\mathrm{OR}=2.5$; $\mathrm{CI}=1.2$ - 5.0).

There was no statistical difference between the two groups for the mean time interval between parietal incision and fetal extraction $(6.8 \pm 4.4$ minutes versus $4.7 \pm$ 1.9 minutes; $\mathrm{P}=0.40)$, as well as the mean duration of surgery $(6.8 \pm 4.4$ minutes versus $4.7 \pm 1.9$ minutes; $\mathrm{P}=$ $0.40)$. However, the mean blood loss was higher in women with excessive gestational weight gain (771.4 \pm $211.2 \mathrm{ml}$ versus $621.3 \pm 171.9 \mathrm{ml}$; $\mathrm{P}<0.001)$. The two groups were similar for mean hospital stay ((5.8 \pm 1.9 days versus $6.2 \pm 3.9$ days; $\mathrm{P}<0.88$ ) and neonatal death $(\mathrm{P}=0.17)$.

In women delivered by cesarean section, excessive weight gain during pregnancy predisposed to (Tables 3-6): time interval from parietal incision to fetal extraction of more than five minutes $(\mathrm{P}<0.001$; $\mathrm{RR}=1.9$; $\mathrm{CI}$ $=1.6-7.0)$, duration of cesarean section more than 60 minutes $(\mathrm{P}=0.002 ; \mathrm{RR}=1.8 ; \mathrm{CI}=1.4-6.1)$, blood loss more than $1000 \mathrm{ml}$ during surgery $(\mathrm{P}=0.04$; $\mathrm{RR}=1.8$; $\mathrm{CI}=1.1$ - 14.6), post-operative maternal complications $(\mathrm{P}=0.005 ; \mathrm{RR}=2.3 ; \mathrm{CI}=1.5-18.7)$, especially sepsis $(\mathrm{P}=0.02 ; \mathrm{RR}=2.1 ; \mathrm{CI}=1.2-14.4)$, fetal weight $>3.5$ $\mathrm{kg}(\mathrm{P}<0.001 ; \mathrm{RR}=4.4 ; \mathrm{CI}=1.9-10.2)$ and macrosomia $(\mathrm{P}=0.026 ; \mathrm{RR}=3.8 ; \mathrm{CI}=1.1-17)$.

Table 2. Comparison of the preoperative variables between the group with excessive weight gain $(n=56)$ and the group without excessive weight gain $(n=75)$.

\begin{tabular}{cccc}
\hline Variables & $\begin{array}{c}\text { Excessive weight } \\
\text { gain n (\%) }\end{array}$ & $\begin{array}{c}\text { No excessive weight } \\
\text { gain n (\%) }\end{array}$ & $\mathrm{P}$ \\
\hline Maternal age (years) & & \\
\hline$<20$ & $1(1.8)$ & $2(2.7)$ & 0.61 \\
{$[20-25]$} & $5((8.9)$ & $13(17.3)$ & 0.13 \\
{$[25-30]$} & $19(33.9)$ & $22(29.3)$ & 0.35 \\
{$[30-35]$} & $15(26.8)$ & $26(34.7)$ & 0.22 \\
$\geq 35$ & $16(28.6)$ & $12(16.0)$ & 0.06 \\
\hline Parity & & & \\
\hline 0 & $26(46.4)$ & $51(68.0)$ & 0.01 \\
$\geq 1$ & $30(53.6)$ & $24(32.0)$ & \\
\hline Gestational age & & & 0.074 \\
\hline$<37$ SA & $12(21.4)$ & $64(10.7)$ & 0.103 \\
{$[37$ - 42 SA } & $42(75.0)$ & $64(4.0)$ & 0.636 \\
\hline 42 SA & $2(3.6)$ &
\end{tabular}


Table 3. Comparison of the indications of cesarean section between the group with excessive weight gain $(\mathrm{n}=56)$ and the group without excessive weight gain $(n=75)$.

\begin{tabular}{ccccc}
\hline Variables & Excessive weight gain n (\%) & No excessive weight gain n (\%) & P & Relative risk (95\% CI*) \\
\hline Scarred uterus & $11(19.6)$ & $22(29.4)$ & 0.144 & $0.7(0.3-1.3)$ \\
Cephalopelvic disproportion & $15(26.8)$ & $13(17.3)$ & 0.138 & $1.4(0.8-4.0)$ \\
Macrosomia & $6(10.6)$ & $1(1.3)$ & 0.024 & $2.1(1.5-24.3)$ \\
Preeclampsia/ eclampsia & $8(14.3)$ & $5(6.7)$ & 0.126 & $1.5(0.7-7.3)$ \\
Fetal distress & $3(5.4)$ & $6(8.0)$ & 0.410 & $0.8(0.2-2.7)$ \\
Malpresentation & $3(5.4)$ & $6(8.0)$ & 0.410 & $0.8(0.2-2.7)$ \\
Cord accidents & $2(3.6)$ & $5(6.7)$ & 0.357 & $0.7(0.1-2.7)$ \\
Others & $8(14.3)$ & $13(17.3)$ & 0.412 & $0.9(0.3-2.0)$ \\
\hline
\end{tabular}

${ }^{*} \mathrm{CI}=$ Confidence Interval.

Table 4. Comparison of the per-operative variables between the group with excessive weight gain $(n=56)$ and the group without excessive weight gain $(n=75)$.

\begin{tabular}{|c|c|c|c|c|}
\hline Variables & Excessive weight gain n (\%) & No excessive weight gain n (\%) & $\mathbf{P}$ & Relative risk $\left(95 \% \mathrm{CI}^{*}\right)$ \\
\hline \multicolumn{5}{|c|}{ Type of the cesarean section } \\
\hline Emergency & $36(64.3)$ & $56(74.7)$ & \multirow{2}{*}{0.14} & $0.8(0.3-1.3)$ \\
\hline Elective & $20(35.7)$ & $19(25.3)$ & & $1.3(0.8-3.5)$ \\
\hline \multicolumn{5}{|l|}{ Parietal incision } \\
\hline Transverse & $54(94.4)$ & $69(92.0)$ & \multirow{2}{*}{0.25} & $1.76(0.5-11.6)$ \\
\hline Sub-umbilical and medial & $2(3.6)$ & $6(8.0)$ & & $0.6(0.08-2.2)$ \\
\hline \multicolumn{5}{|l|}{ Type of anesthesia } \\
\hline General & $17(30.4)$ & $28(37.3)$ & \multirow{2}{*}{0.26} & $0.8(0.3-3.5)$ \\
\hline Spinal & 39 (69.6) & 47 (62.7) & & $1.2(0.6-2.8)$ \\
\hline \multicolumn{5}{|l|}{ Grade of the surgeon } \\
\hline Obstetrician & 35 (37.5) & $37(7.4)$ & \multirow{2}{*}{0.09} & $1.4(0.8-3.5)$ \\
\hline Resident & $21(62.5)$ & 38 (92.6) & & $0.7(0.3-1.2)$ \\
\hline \multicolumn{5}{|c|}{ Time interval from parietal incision to fetal extraction } \\
\hline$>5$ minutes & $30(53.6)$ & $19(25.3)$ & \multirow{2}{*}{0.001} & $1.9(1.6-7.0)$ \\
\hline$\leq 5$ minutes & $26(46.4)$ & $56(74.7)$ & & $0.5(0.14-0.6)$ \\
\hline \multicolumn{5}{|c|}{ Duration of the cesarean section } \\
\hline$>60$ minutes & $30(53.6)$ & $21(28.0)$ & \multirow{2}{*}{0.002} & $1.8(1.4-6.1)$ \\
\hline$\leq 60$ minutes & $26(46.4)$ & $54(72.0)$ & & $0.55(0.17-0.7)$ \\
\hline \multicolumn{5}{|l|}{ Blood loss } \\
\hline$>1000 \mathrm{ml}$ & $8(14.3)$ & $3(4.0)$ & \multirow{2}{*}{0.04} & $1.8(1.1$ - 14.6) \\
\hline$\leq 1000 \mathrm{ml}$ & $48(85.0)$ & $72(96.0)$ & & $0.55(0.07-0.9)$ \\
\hline
\end{tabular}

${ }^{*} \mathrm{CI}=$ Confidence Interval.

Table 5. Comparison of fetal variables between the group with excessive weight gain $(n=56)$ and the group without excessive weight gain $(\mathrm{n}=75)$.

\begin{tabular}{|c|c|c|c|c|}
\hline Variables & Excessive weight gain n (\%) & No excessive weight gain n (\%) & $\mathbf{P}$ & Relative risk (95\% CI') \\
\hline \multicolumn{5}{|l|}{ Fetal birth weight } \\
\hline$<2500 \mathrm{~g}$ & $8(14.3)$ & $10(13.3)$ & 0.76 & $1.1(0.4-3.2)$ \\
\hline$[2500-3500 \mathrm{~g}]$ & $25(44.6)$ & $56(74.7)$ & $<0.001$ & $0.5(0.1-0.7)$ \\
\hline$[3500-4000 \mathrm{~g}]$ & $13(23.2)$ & $6(8.0)$ & 0.009 & $3.1(1.3-10.6)$ \\
\hline$\geq 4000 \mathrm{~g}$ & $8(14.9)$ & $3(4.0)$ & 0.026 & $3.8(1.1-17)$ \\
\hline$\geq 3500 \mathrm{~g}$ & $21(14.9)$ & $9(4.0)$ & $<0.001$ & $4.4(1.9-10.2)$ \\
\hline \multicolumn{5}{|c|}{ Fifth minute Apgar score } \\
\hline$<7$ & $7(12.5)$ & $9(12.0)$ & \multirow{2}{*}{0.64} & $1.03(0.4-2.7)$ \\
\hline$\geq 7$ & $49(87.5)$ & $66(88.0)$ & & $0.97(0.35-2.7)$ \\
\hline
\end{tabular}

${ }^{*} \mathrm{CI}=$ Confidence Interval. 
Table 6. Comparison of the post-operative variables between the group with excessive weight gain $(\mathrm{n}=56)$ and the group without excessive weight gain $(n=75)$.

\begin{tabular}{|c|c|c|c|c|}
\hline Variables & Excessive weight gain n (\%) & No excessive weight gain n (\%) & $\mathbf{P}$ & Relative risk (95\% CI*) \\
\hline \multicolumn{5}{|c|}{ Maternal complications } \\
\hline Presence & $8(14.3)$ & $1(1.3)$ & 0.005 & $2.3(1.5$ - 18.7) \\
\hline sepsis & $6(10.7)$ & $1(1.3)$ & 0.02 & $2.1(1.2-14.4)$ \\
\hline Postpartum hemorrhage & $2(3.6)$ & $0(0.0)$ & 0.18 & $2.39( \pm \infty)$ \\
\hline \multicolumn{5}{|c|}{ Duration of hospital stay after operation } \\
\hline$>5$ days & $12(21.4)$ & $14(18.7)$ & \multirow{2}{*}{0.43} & $1.1(0.5-2.8)$ \\
\hline$\leq 5$ days & 44 (88.5) & $61(81.3)$ & & $0.9(0.35-2.0)$ \\
\hline \multicolumn{5}{|l|}{ Neonatal death } \\
\hline Yes & $2(3.6)$ & $7(9.3)$ & & $0.5(0.08-1.7)$ \\
\hline No & $54(96.4)$ & $68(90.7)$ & 0.17 & $1.99(0.6-13.2)$ \\
\hline
\end{tabular}

${ }^{*} \mathrm{CI}=$ Confidence Interval.

\section{DISCUSSION}

Parity $\geq 1$ is the only risk factor of excessive weight gain during pregnancy found in this study. This factor is not commonly found in the available literature. In fact, nulliparity is one of the most commonly reported risk factors of excessive gestational maternal weight gain $[6,10]$, while multiparity is a known risk factor of obesity in women [6]. At the same time, high prepregnancy body mass index is a risk factor for excessive gestational weight gain $[10,11]$. This finding also described in urban and low-income Black American women by HERRING et al. [10], might explain our finding of multiparity as a risk factor of excessive gestational weight gain in Black African women living in an urban low-income setting. This is similar to the publication by CHIN et al. [12] who stated that women with excessive gestational weight gain at their first pregnancy had a 2.6 risk for gestational excessive weight gain in the subsequent pregnancy.

Per-operative complications in our study included: delay in fetal extraction, duration of surgery lasting more than 60 minutes and excessive blood loss. Even though delay in fetal extraction and long duration of surgery may be understood by practical difficulties in performing the cesarean section, these findings are rarely reported in the available literature, especially in case of excessive gestational weight gain.

Excessive blood loss during cesarean section has some reported risk factors [8]. Excessive weight gain during pregnancy is rarely part of these identified risk factors. However, obesity is a well known and published risk factor of post-partum hemorrhage [13,14]. Probably because of our limited sample size, statistical analysis failed to identify post-partum hemorrhage as related to excessive weight gain, even though two cases of postpartum hemorrhage were found among women with excessive gestational weight gain.

One of the postoperative complications associated with excessive gestational weight gain in our study is infection, mainly endometritis. This finding, though not com- monly reported with excessive gestational weight gain, is in conformity with the published data on the complications of cesarean section in obese patients $[14,15]$. In fact, cesarean section in obese patients is found to multiply by three the risk of endometritis and by two the risk of wound infection [14].

It was also found that excessive gestational weight gain was a risk factor for fetal birth weight $>3.5 \mathrm{~kg}$ and macrosomia. This finding is the most commonly found fetal consequence of excessive gestational maternal weight gain [2-6] and is one of the explanations of the increased cesarean delivery rate in women with excessive gestational weight gain $[2-4,6]$.

However, the factors that might limit the quality of our results are: the small sample size; the lack of multivariate analysis; and the fact that early pregnancy weight was taken by care providers using different weighting scales. All these might have given some bias to our results.

\section{CONCLUSIONS}

Excessive weight gain during pregnancy predisposes to a delay in fetal extraction, a longer duration of surgery, excessive blood loss during surgery, post-operative maternal morbidity and high fetal birth weight.

A systematic screening of excessive weight gain based on the Institute of Medicine's guidelines should be offered to all pregnant women, so as to prevent as much as possible the identified adverse effects of excessive gestational weight gain on cesarean outcome in our setting.

\section{DECLARATION OF CONFLICTING INTERESTS}

None declared.

\section{FUNDING}

This research received no specific grant from any funding agency in the public, commercial, or not-for-profit sectors. 


\section{REFERENCES}

[1] Institute of Medicine and National Research Council (2009) Weight gain during pregnancy: Reexamining the guidelines. The National Academies Press, Washington DC.

[2] Koh, H., Ee, T.X., Malhotra, R., Allen, J.C., Tan, T.C. and Ostbye, T. (2013) Predictors and adverse outcomes of inadequate or excessive gestational weight gain in an Asian population. Journal of Obstetrics and Gynaecology Research, 39, 905-913. http://dx.doi.org/10.1111/j.1447-0756.2012.02067.x

[3] Drehmer, M., Duncan, B.B., Kac, G. and Schmidt, M.I. (2013) Association of second and third trimester weight gain in pregnancy with maternal and fetal outcomes. PLoS One, 8, e54704. http://dx.doi.org/10.1371/journal.pone.0054704

[4] Chung, J.G., Taylor, R.S., Thompson, J.M., Anderson, N.H., Dekker, G.A., Kenny, L.C., et al. (2013) Gestational weight gain and adverse pregnancy outcomes in a nulliparous cohort. European Journal of Obstetrics \& Gy-necology and Reproductive Biology, 167, 149-153. http://dx.doi.org/10.1016/j.ejogrb.2012.11.020

[5] Costa, B.M., Paulinelli, R.R. and Barbosa, M.A. (2012) Association between maternal and fetal weight gain: Cohort study. Sao Paulo Medical Journal, 130, 242-247. http://dx.doi.org/10.1590/S1516-31802012000400007

[6] Gaillard, R., Durmuş, B., Hofman, A., Mackenbach, J.P., Steegers, E.A. and Jaddoe, V.W. (2013) Risk factors and outcomes of maternal obesity and excessive weight gain during pregnancy. Obesity (Silver Spring), 21, 1046-1055. http://dx.doi.org/10.1002/oby.20088

[7] Chu, K., Cortier, H., Maldonado, F., Mashant, T., Ford, N. and Trelles, M. (2012) Cesarean section rates and indications in sub-Saharan Africa: A multi-country study from Médecins sans Frontières. PLoS One, 7, e44484. http://dx.doi.org/10.1371/journal.pone.0044484

[8] Kolas, T., Oian, P. and Skjeldestad, F.E. (2010) Risks for peroperative excessive blood loss in cesarean delivery. Acta Obstetricia et Gynecologica Scandinavica, 89, 658663. http://dx.doi.org/10.3109/00016341003605727

[9] Schulz, K.F. and Grimes, D.A. (2005) Sample size calculations in randomized trials: Mandatory and mystical. Lancet, 365, 1348-1353.

http://dx.doi.org/10.1016/S0140-6736(05)61034-3

[10] Herring, S.J., Nelson, D.B., Davey, A., Klotz, A.A., Dibble, L.V., Oken, E., et al. (2012) Determinants of excessive gestational weight gain in urban, low-income women. Womens Health Issues, 22, 439-446. http://dx.doi.org/10.1016/j.whi.2012.05.004

[11] Kraschnewski, J.L., Chuang, C.H., Downs, D.S., Weisman, C.S., McCamant, E.L., Baptiste-Roberts, K., et al. (2013) Association of prenatal physical activity and gestational weight gain: Results from the first baby study. Womens Health Issues, 23, 233-238. http://dx.doi.org/10.1016/j.whi.2013.04.004

[12] Chin, J.R., Krause, K.M., Ostbye, T., Chowdhury, N., Lovelady, C.A. and Swamy, G.K. (2010) Gestational weight gain in consecutive pregnancies. American Journal of Obstetrics \& Gynecology, 203, 279. http://dx.doi.org/10.1016/j.ajog.2010.06.038

[13] Fyfe, E.M., Thompson, J.M., Anderson, N.H., Groom, K.M. and McCowan, L.M. (2012) Maternal obesity and postpartum haemorrhage after vaginal and caesarean delivery among nulliparous women at term: A retrospective cohort study. BMC Pregnancy Childbirth, 12, 112. http://dx.doi.org/10.1186/1471-2393-12-112

[14] Machado, L.S. (2012) Cesarean section in morbidly obese parturients: Practical implications and complications. North American Journal of Medical Sciences, 4, 13-18. http://dx.doi.org/10.4103/1947-2714.92895

[15] Mandal, D., Manda, S., Rakshi, A., Dey, R.P., Biswas, S.C. and Banerjee, A. (2011) Maternal obesity and pregnancy outcome: A prospective analysis. Journal of the Association of Physicians of India, 59, 486-489. 